\title{
TWO-POINT BOUNDARY VALUE PROBLEMS ASSOCIATED WITH NON-LINEAR FUZZY DIFFERENTIAL EQUATIONS
}

\author{
V. LAKSHMIKANTHAM, K. N. MURTY, AND J. TURNER
}

Abstract. This paper presents a criteria for the existence and uniqueness of solutions to two point boundary value problems associated with a second order non-linear fuzzy differential equations. The main tools employed are estimates on Green's function, Ascoli's Lemma and a fixed point theorem of Banach.

Mathematics subject classification (2000): 34A10, 26E50, 34B15.

Key words and phrases: Fuzzy differential equations, two-point boundary value problems, fixed point theorem, Greens function, existence and uniqueness.

\section{REFERENCES}

[1] P. B. BAily, L. F. Shampine AND P. E. WAltman, Nonlinear two-point boundary value problems, Academic Pres, New York and London, 1968.

[2] V. LAKSHMIKANTHAM AND R. N. MOHAPATRA, Basic properties of solutions of Fuzzy differential equations (to apper).

[3] O. Kaleva, Fuzzy differential equations, Fuzzy Sets and Systems 24 (1987), 301-317.

[4] O. KaleVA, The Cauchy problem for fuzzy differential equations, Fuzzy Sets and Systems 35 (1990), 389-396.

[5] J. J. NIETO, The Caucky problem for continuous fuzzy differential equations, Fuzzy Sets and Systems 2500 (1997), 001-006.

[6] H. RAdSTRom, An embedding theorem for space of convex sets, Proc. Amer. Math. Soc 3 (1952), 165-169. 